\title{
Blockchain technology - a new approach in business environment
}

\author{
Olga Bucovetchi ${ }^{1, *}$, Dorel Badea ${ }^{2}$, and Radu D. Stanciu ${ }^{1}$ \\ ${ }^{1}$ University "Politehnica of Bucharest", Economic Engineering Department, 313, Spl. Independentei, 060042, Bucharest, Romania \\ 2"Nicolae Bălcescu” Land Forces Academy, Department of Management, 3-5, Revolutiei St., 550170, Sibiu, Romania
}

\begin{abstract}
Given the newest trends in business and the growing interest towards Internet of Things, it became natural that economic environment switched the paradigm of classical business model. Blockchain technology is a very timely topic of discussion both in academic environment and outside it. This element was proven by authors when analyzing the topic towards the number of publication releases and the search engine queries. Furthermore, the authors shaped the framework of blockchains' development highlighting the main advantages and disadvantages for Industry 4.0.
\end{abstract}

\section{Introduction}

Specialists discuss that the world is at the start of a new industrial revolution, which is considered the fourth revolution and is called "Industry 4.0" [1-5]. The manner of doing business in any company changes due to several factors, such as: globalization, high level competition, information becoming a key resource or digitalization (both of work space and business environment). Connecting many products to the internet, the presence of highly sensitive sensors, the expansion of wireless communications, developing intelligent machine and real-time data analysis have the potential to turn the way the production is done. Given this, the business environment tends to adapt to this shift of paradigm. As a consequence, businesses turn to cloud or at least try embed more and more features related to Internet of things, not only in terms of marketing strategy, but also by integrating innovative elements such as cryptology or cryptography..

In 2008, Nakamoto [6] introduced the concept of blockchain without using the exact term yet explaining the technology by presenting Bitcoin as virtual currency. Bitcoin is known as the first virtual currency. Yet, in only 10 years, the number of known virtual currencies grew to more then 1590 [7], the most traded elements being the following:

Table 1. Top 5 most traded virtual currencies

\begin{tabular}{|l|c|}
\hline \multicolumn{1}{|c|}{ Currency } & Market capitalisation [\$] \\
\hline Bitcoin & $141,568,525,343$ \\
\hline Ethereum & $70,160,750,450$ \\
\hline Ripple & $26,661,640,812$ \\
\hline Bitcoin Cash & $20,283,402,474$ \\
\hline EOS & $11,347,212,707$ \\
\hline
\end{tabular}

Until recently there was no official definition of "blockchain". Still, in March 2018, blockchain was defined as "a digital database containing information (such as records of financial transactions) that can be simultaneously used and shared within a large decentralized, publicly accessible network" and also as "the technology used to create such a database" [8].

Expert Aaron Montemayor Walker explains the technology in few easy steps [9]:

- One party requests a transaction

- Requested transactions are funneled into a P2P (peer-topeer) network and broadcast to each individual computer (node)

- Individual nodes receive the request and validate the transaction using an algorithm

- Approved transactions are represented as blocks and added to a public ledger

- Once the block is added to an existing chain, transactions are complete and permanent.

A blockchain is characterized by censorship resistance, immutability and global usability, and has a global network of validators called miners, who maintain it through block rewards, named crypto tokens [10,11].

The paper presents, in great, a literature research towards the concept of "blockchain technology". The literature research shall represent the starting point for a deeper analysis in order to help practitioners reshape their businesses, in order to become more globally competitive.

\section{Research methodology}

The research methodology had the following steps:

- Enquiring Web if Science database towards the number of publications that had "blockchain" as topic and assessing the categories regarding those results

- Investigating "blockchain" as "search topic" on Google Trends.

\footnotetext{
* Corresponding author: olga.bucovetchi@upb.ro
} 
- After the comprehensive trend analyses, a wide-ranging literature review was conducted and summarized in order to shape the advantages, disadvantages and possible applications of blockchain technology as the IT impact on the company is not only felt from the outside environment, but also from within the company

Web of Science is an online subscription-based scientific citation indexing service that provides a comprehensive citation search.

It gives access to multiple databases that reference cross-disciplinary research, which allows for in-depth exploration of specialized sub-fields within an academic or scientific discipline. [12]

Google Trends is a public web facility of Google Inc., based on Google Search, that shows how often a particular search-term is entered relative to the total search-volume across various regions of the world, and in various languages.

The horizontal axis of the main graph represents time (starting from 2004), and the vertical is how often a term is searched for relative to the total number of searches, globally. [13]

\section{Results}

The level of interest towards "blockchain" embedded two layers: the academic environment and the non-specialists' environment. The authors assumed that the more attractive the topic is, the more many publications are released.

This research was conducted on the $1^{\text {st }}$ of May 2018. We collected a number of 594 of publications within the selected period, namely 2013-2017.

As it can easily be observed, the evolution is positive, having an exponential increasing trend. This trend is presumed to be a consequence of the novelty of the topic.

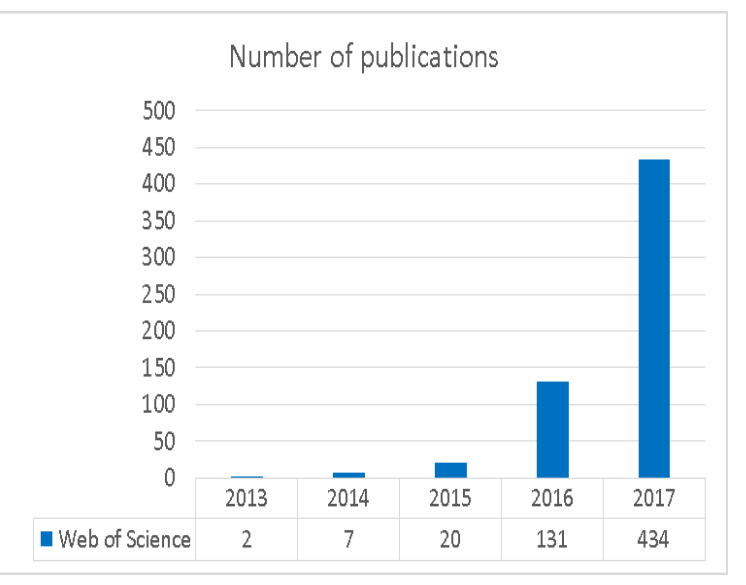

Fig. 1. Evolution of number of publications on "blockchain"

In terms of "Web of Science" domain, most papers deal more with the technology as engineering process, only recently, scientists shifting the paradigm to business features (Table 2).

Table 2. Top 10 papers categories on "blockchain"

\begin{tabular}{|l|c|}
\hline \multicolumn{1}{|c|}{ Web of Science Categories } & No. of papers \\
\hline $\begin{array}{l}\text { computer science information } \\
\text { systems }\end{array}$ & 180 \\
\hline $\begin{array}{l}\text { engineering electrical } \\
\text { electronic }\end{array}$ & 165 \\
\hline $\begin{array}{l}\text { computer science theory } \\
\text { methods }\end{array}$ & 162 \\
\hline telecommunications & 95 \\
\hline $\begin{array}{l}\text { computer science } \\
\text { interdisciplinary applications }\end{array}$ & 81 \\
\hline $\begin{array}{l}\text { computer science software } \\
\text { engineering }\end{array}$ & 63 \\
\hline business finance & 49 \\
\hline $\begin{array}{l}\text { computer science artificial } \\
\text { intelligence }\end{array}$ & 46 \\
\hline $\begin{array}{l}\text { computer science hardware } \\
\text { architecture }\end{array}$ & 28 \\
\hline business \\
\hline
\end{tabular}

As for the non-specialists' interest towards blockchain, Google trends revealed that the interest reached a pick at the end of 2017, nowadays, the trend being negative. This is considered to be also an effect of the negative marketing campaigns conducted by the conventionall financial organizations. Furthermore, many governments try to establish an restictive regulatory framework for "smart contracts".

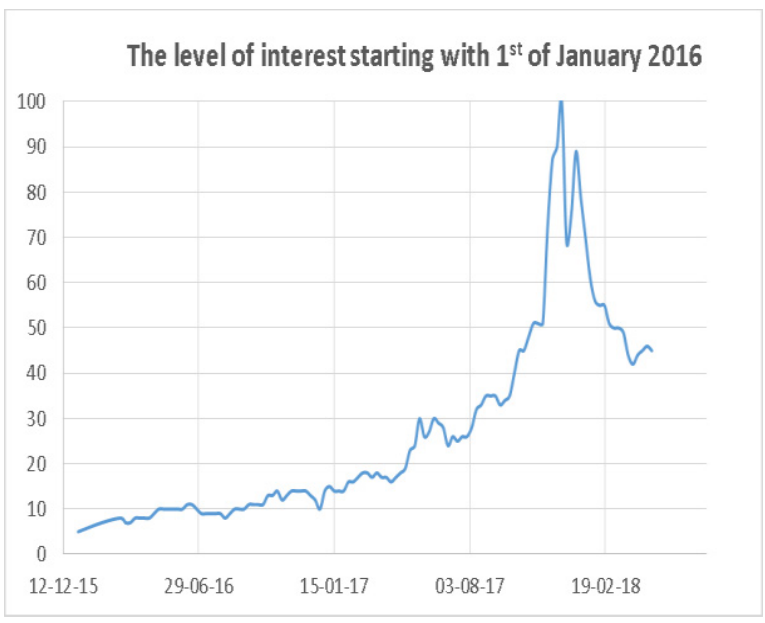

Fig. 2. People's interest towards "blockchain"

The numbers associated in a certain period with interest (as seen in Fig. 2) represent the search interest associated with the highest point in the chart for the specified region and time. Value 100 is related with the maximum popularity of the term. We selected the period after $1^{\text {st }}$ of January 2016 as, starting that date, Google trends implemented a more performant tool in collecting and analyzing these particular type of data.

One may conclude that the trend shifted to negative as Bitcoin value started to decrease. As it can be observed in following tables, the search of "blockchain technology" on Google is correlated mostly with business environment (Bitcoin, wallet, investment, ...) 
Table 3. Top 5 search terms related to blockchain

\begin{tabular}{|l|c|}
\hline \multicolumn{1}{|c|}{ Searched topic } & Scoring \\
\hline Blockchain & 100 \\
\hline Bitcoin & 14 \\
\hline Wallet & 6 \\
\hline Ethereum & 3 \\
\hline Blockchain.info & 3 \\
\hline
\end{tabular}

Scoring is done on a relative scale, where the most frequently searched topic has 100 points.

Table 4. Related entities.

\begin{tabular}{|l|l|}
\hline Term of search & Results \\
\hline Ethereum & massive growth \\
\hline Cryptocurrency & massive growth \\
\hline Technology & massive growth \\
\hline Investment & massive growth \\
\hline Ripple & massive growth \\
\hline
\end{tabular}

According to Google trends "The results marked "Massive Growth" have shown an increase almost impossible to measure, most likely because the topics are new and previously there were few searches for them (or not at all)".

Table 5. Top 5 related queries to "blockchain"

\begin{tabular}{|l|l|}
\hline No. & Related query \\
\hline 1. & blockchain bitcoin \\
\hline 2. & bitcoin \\
\hline 3. & blockchain wallet \\
\hline 4. & blockchain technology \\
\hline 5. & what is blockchain \\
\hline
\end{tabular}

Another layer of the analysis took into consideration the interest of academia in blockchain technology vs. the interest of business sector. It was revealed that the scientific interest is not followed by a putting in practice of the theoretical findings.

Table 6. Top 5 most productive countries

\begin{tabular}{|l|c|}
\hline \multicolumn{1}{|c|}{ Country } & No. of papers \\
\hline USA & 162 \\
\hline China & 107 \\
\hline England & 64 \\
\hline Germany & 49 \\
\hline Italy & 39 \\
\hline
\end{tabular}

Despite the results retrieved from Web of Science (see Table 6), L. Lewis states that top 5 countries leading in blockchain industry is [14]:
- Switzerland

- United Kingdom

- Estonia

- Singapore

- Cyprus

Even if most people refer to "blockchain" only in terms of crypto-currencies, this technology has multiple applications: [15]

- As a system of record:

- For digital identity

- For authentication in certain context (tokenization)

- For governments

- For financial institutions

- For audit trails

- As a platform:

- For smart contracting

- For automated governance

- For markets

- For streamlining of clearing and settlement

- For automating regulatory compliance

There should be mentioned several blockchain platforms that embed those elements:

- Bitcoin [16] is the first and best known blockchain network, mainly oriented on crypto-currency transactions

- Ethereum [17] was launched as an open-source blockchain platform in 2015, defines smart contracts and is designed for a large variety of decentralized applications (DApps)

- Hyperledger [18] is a Linux Foundation Project and incubates and promotes a range of business blockchain technologies, including distributed ledger frameworks, smart contract engines, client libraries, graphical interfaces, utility libraries and sample applications.

The advantages of the blockchain technology are the following [ 10,19]:

- self-sovereignty - users identify themselves and maintain control over the storage and management of personal data;

- trust - the technical infrastructure offers secure operations (payments or issue of certificates);

- transparency and provenance - to perform transactions in knowledge that each party has the capacity to enter into that transaction;

- immutability - records are written and stored permanently, without the possibility of modification;

- disintermediation - no need for a central controlling authority to manage transactions or keep records;

- collaboration - ability of parties to transact directly with each other without the need for third-parties

- durability - the decentralized networks offer no central point of failure

One the other hand, we shall mention also the disadvantages, as for example:

- large energy consumption

- uncertain regulatory status

- the novelty of the technology

- performance - it is slower than a centralized database

- costs 


\section{Conclusions}

As Holotescu [10] mentioned: "blockchain has surged from a technology with narrow applications related to digital currencies, to one with important applications in many domains, drawing attention to policy makers at different levels too.

In spite of the evidences that blockchain could solve some of the most pressing problems in business and society today, there is a gap in turning many use cases into reality, particularly from a strategic viewpoint.

In October 2017, Pannetta mentioned blockchain as a strategic technology trend it "holds the promise to change industries, and although the conversation often surrounds financial opportunities, blockchain has many potential applications in government, healthcare, content distribution, supply chain and more." [20]

Furthermore, being such new technology, there are many risks that might occur as there was not enough time of testing it therefore "black swan" events are highly probable.

Nevertheless, we shall mention that specialists predict that $[9,21,22]$ :

- major institutions will offer pilot programs to the public

- blockchain will reshape the future

- financial institutions will invest more and more in blockchain technology

- blockchain - IoT (Internet of Things) will boom

\section{References}

1. H. Lasi, H.G. Kemper, P. Fettke, T. Feld, M. Hoffman, Industry 4.0, Business \& Information Systems Engineering $6 \quad 4 \quad$ (2014) doi: 10.1007/s12599-014-0334-4

2. SY Wang, JF Wan, DQ Zhang, D. Li, Ch. Zhang Towards smart factory for industry 4.0: a selforganized multi-agent system with big data based feedback and coordination, Computer Networks, 101 (2016) doi: 10.1016/j.comnet.2015.12.017

3. D. Ivanov, A. Dolgui, B. Sokolov, F. Werner, M. Ivanova, A dynamic model and an algorithm for short-term supply chain scheduling in the smart factory industry 4.0, Int. J. Prod Research 54 (2) (2016) DOI: 10.1080/00207543.2014.999958
4. M. Stonebraker, S. Madden, D. J. Abadi, S. Harizopoulos, N. Hachem, P. Helland, The end of an architectural era (it's time for a complete rewrite), Proceedings of the 33rd International Conference on Very Large Data Bases (VLDB), Vienna, Austria, pp. 1150-1160 (2007)

5. S. Singh, New Mega Trends: Implications for our Future Lives, (Palgrave Macmillan, 2012)

6. S. Nakamoto, Bitcoin: A Peer-to-Peer Electronic Cash System. (2008), available online at: https://bitcoin.org/bitcoin.pdf

7. https://coinmarketcap.com/all/views/all/

8. https://www.merriamwebster.com/dictionary/blockchain

9. https://blog.g2crowd.com/blog/trends/cybersecurity/ 2018-cs/blockchain/

10. C. Holotescu, Understanding Blockchain Opportunities and Challenges, The $14^{\text {th }}$ International Scientific Conference eLearning and Software for Education Bucharest, April 19-20, 2018, DOI: 10.12753/2066-026X-18-253

11. R. Shulman, How Millionaire Jeremy Gardner And Jinglan Wang Built The Largest Blockchain Education Network (Forbes, 2018)

12. https://en.wikipedia.org/wiki/Web of Science

13. https://en.wikipedia.org/wiki/Google Trends

14. L. Lewis, Countries Leading the Blockchain Innovation Movement, 2018, available online at: https://tokentarget.com/countries-leading-theblockchain-innovation-movement/

15. https://www.coindesk.com/information/applicationsuse-cases-blockchains/

16. www.bitcoin.org

17. Ethereum.org

18. https://www.hyperledger.org/projects

19. https://www.e-spincorp.com/2017/11/24/pros-andcons-of-blockchain-technology/

20. K. Pannetta, Gartner Top 10 strategic trends for 2018 (2017) available online at: https://www.gartner.com/smarterwithgartner/gartner -top-10-strategic-technology-trends-for-2018/

21. https://www.quora.com/What-is-the-future-ofblockchain

22. https://www.digitaltrends.com/computing/beyondbitcoin-how-blockchain-will-reshape-the-future/ 